\title{
COMPARATIVE STUDY OF THE GROWTH OF OKOUMÉ (AUCOUMEA KLAINEANA PIERRE) SEEDLINGS FROM DIRECT SEEDING TO (WILD) SEEDLINGS HARVESTED IN NATURAL FOREST.
}

\author{
Ayessa Leckoundzou ${ }^{(1,2,3)}$, Mbete Pierre ${ }^{(1,2,3)}$, Douh Chauvelin ${ }^{(1,2,3)}$ and Koubouana Felix ${ }^{(1,2,3)}$ \\ ${ }^{1}$ National School of Agronomy and Forestry (ENSAF) \\ ${ }^{2}$ Laboratory of Tropical Ecology and Applied Geomancy (LETGA). \\ ${ }^{3}$ University Marien Ngouabi (UMNG) \\ http://doi.org/10.35410/IJAEB.2019.183201
}

\begin{abstract}
The study on the comparison of seedling growth of Okoumé (Aucoumea klaineana Pierre) in nursery compared to harvested seedlings (wild plants) in dense forest in Africa takes place at the Nursery of Youbi, a locality located in the department of Kouilou in the Republic of Congo.

Initially, eight hundred seeds of Okoume (Aucoumea klaineana Pierre) had undergone a direct germination test in the same nursery, then we made a selection of thirty (30) seedlings that should constitute the transplanting device in lute with the thirty (30) other seedlings (wildlings) from harvests in natural forest.

In both cases, the work equipment was the same. The transplants in the field should have the same correspondences, therefore the same parameters. The observations were made as well as the measurements. During the treatment of the results, we noticed some differences of growth in both cases, in particular in the follow-up of the development of the plants (average height of the stem). In seedlings, we found an increase of $11 \mathrm{~cm}$ in 12 weeks with an average growth rate of 8.3\%; the curves are stationary during the first two weeks as in the other case, along the experiment we have a broken line curve but here we see a slight growth rate of $9.22 \mathrm{~cm}$.

The average number of leaves in 12 weeks showed that seedlings and wild plants produced an average of 6 leaves.

In the case of the length and the growth of the leaves, it appears that the growth, whatever the seedling or the wild, it is synchronized. Leaves do not develop in the same way in both seedlings and wild plants. The average number of nodes, for example, has been observed, a production of nodes similar to that of the leaf production at the level of the seedlings whereas in the wild, the pace reflects that of the average number of leaves, but it differs with the first two weeks when it remains stationary. The rate of increase of the leaf area remains as insignificant as $16.15 \mathrm{~cm} 2$ for seedlings and $17.52 \mathrm{~cm} 2$ for wildlings. This competition should be applied in the majority of nurseries of the National Reforestation Service (SNR) in order to choose plants with good behavior before transplanting into the forest.
\end{abstract}

Keywords: growth, seedling, wild, okoumé, leaf. 
Vol. 4, No. 03; 2019

ISSN: $2456-8643$

\section{INTRODUCTION}

In Congo the first trials of planting Limba began in the years 1937 to 1949 on an area of 22ha Mbuku N'situ in Mayombe, southern Congo.

Silvicultural activities in the literal sense, carried out from 1949 to 1989 , were carried out by five (5) public bodies, in particular the Congo Forest Corporation, the Forest Reforestation, the National Forestry and Forest Management Office, the Office Congolese Forest and finally the National Reforestation Service.

In 1989, the Congolese Forest Office was transformed into a National Reforestation Service created by Decree No. 89/042 of 21 January 1989, the reforestation service is the extension of a series of organizations charged with applying the policy the country in terms of reforestation. At that time, this service had achieved an area of plants of 7011.59 ha between 1989 and 1998 . (Mapola, 1999).

These figures show that the Congolese forest occupies a primordial place in the human life of Congolese thanks to the multiple functions it provides.

In total, forests in the Republic of Congo cover an estimated area of 22.5 million hectares, or $65 \%$ of the national territory (FAO, 2012). The Congo alone contains nearly $10 \%$ of the dense forests of Central Africa. According to the (CBFP, 2006) the forests of Congo Brazzaville, count about 5000 species of flora. It is the second natural resource after oil and has a huge biodiversity reserve. These forests are of great socio-economic and environmental importance (Forest Code, 2000). They are divided into three main massifs:

The North Massif, which occupies 15 million hectares, including 9 million non-flooded forests with a potential of 130 million cubic meters;

The Chaillu massif in the South with 3.5 million hectares;

The Mayombe Massif in the extreme south with 1.5 million hectares (Boundzanga, 2005).

As for the artificial forest, it covers a significant area with 57000 hectares of forest planted around 1993. The most planted species are eucalyptus and pines in savannah. Limba (Terminalia superba L.) and Okoumé (Aucoumea klaineana Pierre) are also planted, but in natural forest. The Congolese forest contributes more than $11 \%$ of gross domestic product (GDP) and occupies nearly $60 \%$ of the active population. This sector, still little known on the scientific level, is now considered essential for the development of the national economy (Norbert G., and Charles D., 2001).

Studies are therefore encouraged for the development of this national heritage.

(Sist, P., et al., 1998.), thinks that in Kouilou in general and in U.F.A. $\mathrm{n}{ }^{\circ} 2$ Madingo-Kayes in particular, logging without a management plan in the past and with the association of peasant agricultural activities has led to a gradual degradation of the forest ecosystem, particularly in the peripheral zone of Conkouati National Park. -Douli, the practice of shifting cultivation on brulis, 
the artisanal sawing as well as the increase of the needs of the populations on the natural resources contribute to a negative impact of the forest. This state of affairs makes it necessary to think of reforestation, but also of forest conservation, especially on the most endangered species.

For example, the country's forestry administration became aware of forest issues and set up the National Reforestation Service (SNR), which deals with the reforestation of forests, and forced loggers to undertake silvicultural activities. avoid deforestation, preserve biological diversity and promote the regeneration of commercial species.

Whereas tropical forest is a renewable resource mine, its survival depends mainly on the seed and seedling that remain the main organs of dissemination and natural regeneration (Pangou, 1986).

This study has therefore contributed to a flourishing of the reforestation of the two most soughtafter species of the zone and has for general objective, the comparison in nursery of the growth between the seedlings resulting from the direct seeding with that of the harvests (savages) coming from the okoumé forest. The specific objectives of this work are focused on:

The evaluation of the germination percentage of the seeds of (Aucoumea klaineana Pierre) in germoir;

The calculation of the germination rate as well as the follow-up of the development of the seedlings in mean height of the stem, the growth rate of the seedlings (\%);

Evaluation of the average number of leaves in seedlings and wild vines;

Determine the length and width of the leaves in both cases;

Calculate the plastochron rhythm of seedlings and wild plants;

Determine the average number of nodes of seedlings and wildlings;

Calculation of leaf area of seedlings and wildlings

Evaluate the growth rate of leaf area of seedlings and wildlings.

\section{MATERIAL AND METHODS OF STUDY}

Material: To carry out this study, we have two types of material namely:

Plant or biological material;

\section{Technical equipment.}

Plant material) (Figure 1 and 2)

For direct seeding, we used seeds from the Ngoua2 forest station. We went through the natural forest to harvest the seedlings (wildlings). 
Technical equipment. The nursery technical equipment we used is: rakes; wheelbarrows; machetes; sprayers; buckets; garbage cans; pairs of gloves; watering cans; secateurs and phytocels.

For the monitoring of plant growth and development, the material used is as follows: a graduated rule for estimating stem height, leaf length and width, leaf area, and rope to align pots (phytocelles).
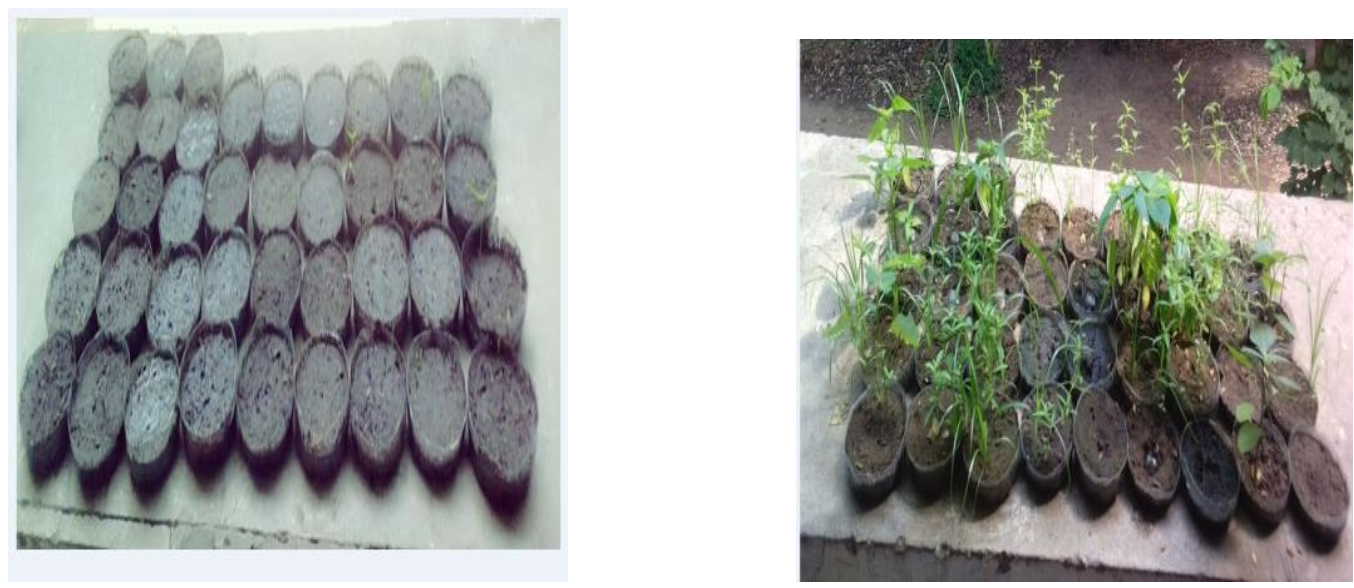

Figure 1. Experimental plant arrangement Figure 2. Outlet seedlings

\section{METHODS}

First part of the study:

\section{Nursery Work:}

The nursery is a landscaped environment to produce the seedlings. It aims to transfer the seedlings to planting to enrich the degraded areas of the forest. Our nursery is located on slightly sloping ground to facilitate the flow of rain water and covers an area of 0.62 hectares including 0.51 ha of usable area and 0.11 ha occupied by the paths. It consists of seedlings of natural forest species, resulting from sowing and various wild plants from development plantations. Only Okoumé plants were the subject of our study.

\section{Seed preparation}

In the nursery, 800 seeds of Aucoumea klaineana Pierre from the forest station of Ngoua2 were used as part of this work. They did not undergo any treatment and were kept in a closed container.

\section{The second part of our work:}

Our sample consisted of thirty (30) sprout seedlings sorted from 800 seeds and thirty (30) wild harvested from the forest. 
Then the seedlings of the seedlings and those of the forest were transplanted into the device. Before transplanting the plants, it should be noted that the 60 selected seedlings had a single leaf and a height varying between 3.4 and $3.6 \mathrm{~cm}$ so they had an identical resemblance with the same criteria. The objectives set by the study were to perform twice a week and for a period of three (3) months.

Sowing and monitoring of Okoumé seeds (Aucoumea klaineana, Pierre)

We did the sowing online. The sowing was carried out in a sprinkler previously filled with black soil of $2 \mathrm{~m}$ long and $1 \mathrm{~m}$ wide. The seeds were sown on the lines and between lines with a spacing of $5 \mathrm{~cm}$ and at a depth of $1 \mathrm{~cm}$.

\section{The lifting rate}

The emergence rate $(\mathrm{T}(\%))$ was calculated as the ratio between the number of seeds raised and the number of seeds sown per hundred:

\section{Mortality rate}

The mortality rate (TM (\%)) was determined by the ratio of the number of dead seedlings after emergence and the total number of seedlings raised per hundred

\section{Growth rate}

From the height measurement data, the growth rate (TC (\%)) of a plant between two (2) successive weeks was calculated according to the ratio of the difference between the average height obtained in the first week and the second week by one hundred

\section{Monitoring plant growth}

The growth of a plant requires knowledge of a number of parameters including: the height of the stems; the number of leaves; the number of nodes on the plants, the length and width of the leaves and the leaf area.

\section{The height of the stems and number of leaves.}

The height of the stems was measured from the neck to the tip of the last most dominant leaf of the plant.

\section{Number of nodes on the plants}

We proceed by simply counting the nodes on each plant

\section{Length and width of leaves}

It is a question of measuring the length and the width of the first sheet left after the cotyledons on each plant. This leaf in alternating position is annealed to a rectangle. The length is measured from the area of insertion between the petiole and the limb to the tip of the limb; the width is measured in the middle of the length. 


\section{The leaf area}

It is calculated by the product of the average length of the leaves and the average width of the leaves

\section{PRESENTATION OF THE RESULTS}

First bet of the study: The germination (raising okoumé) (Aucoumea klaineana Pierre)

The results of the germination of the 800 seeds, allowed us to obtain the optimal germination rate of the seedling in line (Table 1).

Table 1: Percentage germination of seeds of Okoumé (Aucoumea klaineana Pierre) in germiners.

\begin{tabular}{|l|l|l|l|l|}
\hline Observation & Date & lifting & $\begin{array}{l}\text { Cumulative } \\
\text { number }\end{array}$ & Percentage (\%) \\
\hline seedling & $16-01-2017$ & - & - & - \\
\hline $1^{\text {ère }}$ lifting & $26-01-2017$ & 171 & 171 & $\mathbf{2 1}$ \\
\hline $2^{\text {ème }}$ lifting & $29-01-2017$ & 125 & 296 & $\mathbf{3 7}$ \\
\hline $3^{\text {ème }}$ lifting & $03-02-2017$ & 100 & 396 & $\mathbf{4 9 , 5}$ \\
\hline $4^{\text {ème }}$ lifting & $10-02-2017$ & 82 & 478 & $\mathbf{5 9 , 8}$ \\
\hline $5^{\text {ème }}$ lifting & $16-02-2017$ & 54 & 532 & $\mathbf{6 6 , 5}$ \\
\hline $6^{\text {ème lifting }}$ & $28-02-2017$ & 15 & 547 & $\mathbf{6 8 , 4}$ \\
\hline Total & & 547 & & \\
\hline
\end{tabular}

The first round was observed at the end of the tenth (10th) day after sowing, unlike other seeds that germinated after about two (2) weeks.

The question is, how long did the seeds fall before they were picked?

Germination rate

Of 800 seeds sown, 547 seeds were raised, ie a germination rate of $68.4 \%$. However, 253 seeds did not germinate or a significant mortality rate of $46.2 \%$.

Follow-up of the device during the second part of the study: After transplanting the seedlings in the field:

Follow-up of the development of the plants (average height of the stem) 
Figures 3 and 4 illustrate growth in height of seedlings and wildlings. The curve of the seedlings is linear from the 3rd to the 12th week while that of the wilds is in the shape of S.

Seedlings from the seeds

After two weeks of transplanting, seedlings measure an average of $3.4 \mathrm{~cm}$ in height. High growth can be seen from the third week when the seedlings reach about $4.48 \mathrm{~cm}$ average height, this high growth continues until reaching a maximum average height of $14 \mathrm{~cm}$. We found that this sample has an increase of nearly $11 \mathrm{~cm}$ in 12 weeks, an average growth rate of 8.3\% (Figure 1).

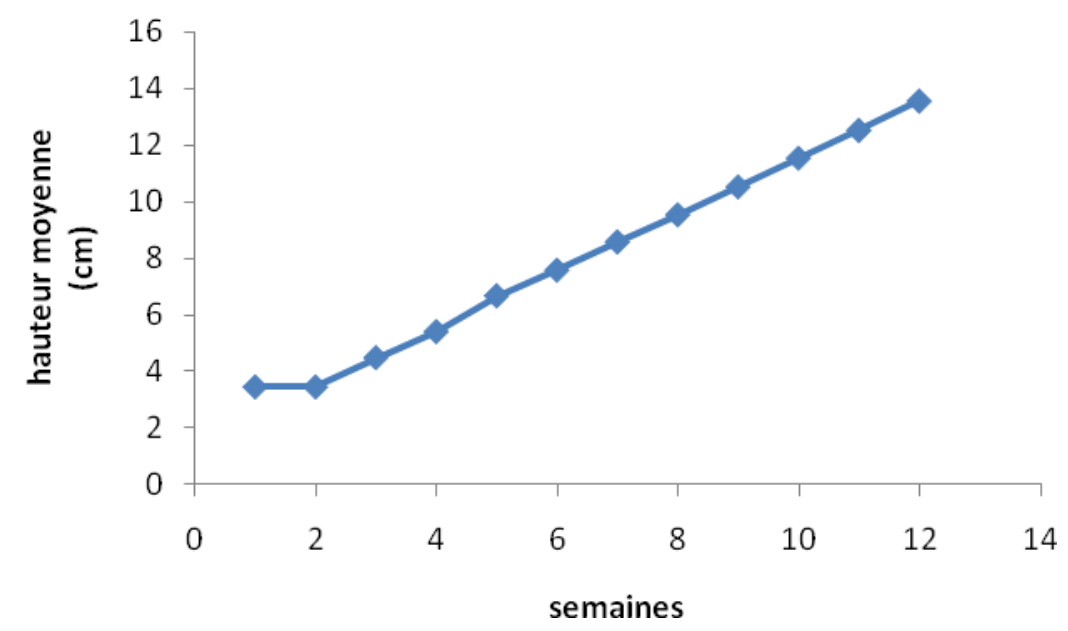

Figure 1: Evolution of shoot height of seedlings as a function of time

\section{The savages}

There is a rapid growth of the stems of the 2nd until the 5th week. It remains stable at the 6th week. Resumption of stem growth reappears for a second time when the stems reach an average height of $7.6 \mathrm{~cm}$ from the 7th week to the 9th week. There is a slowdown at the 10th week followed by a recovery between the 11th and 12th week when the stems reach a maximum average height of $13 \mathrm{~cm}$.

This sample increased by about $9 \mathrm{~cm}$ in 12 weeks, an average growth rate of $12.18 \%$.

\section{From the forest savage:}

A note was made on the growth of wild-type (Figure 2), namely:

High growth (acceleration); slowdown; the growth recovery. 


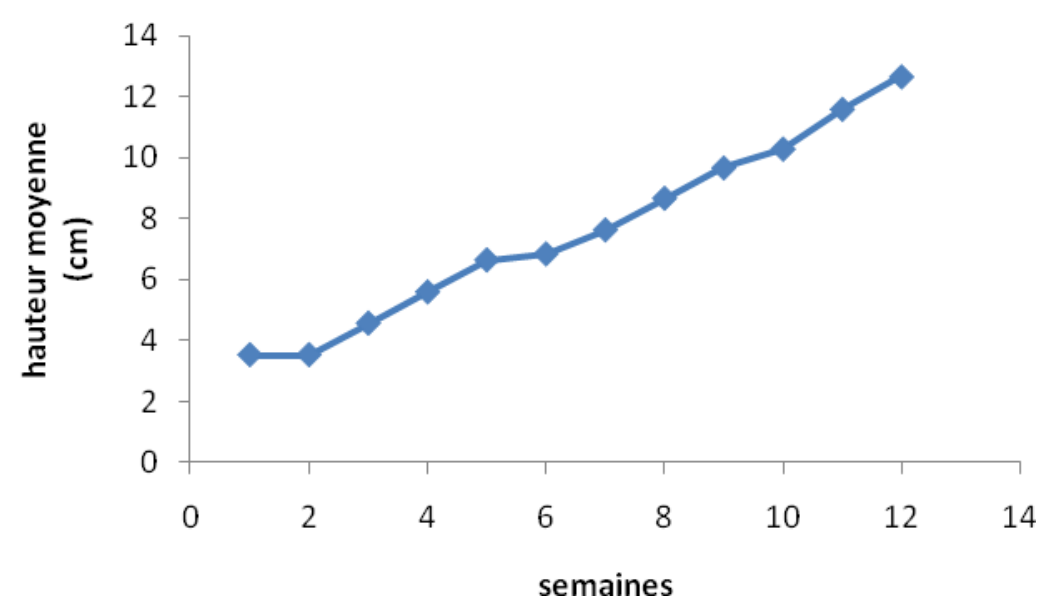

Figure 2: Evolution of the height of the stems of the wilds as a function of time.

The pace of these two curves is stationary during the first two weeks, this stability is explained by the time of adaptation of the plants to the new substrate (Table 2).

Table 2: Growth rates of seedlings and wild vines (\%).

\begin{tabular}{|l|l|l|}
\hline Period per week & seedlings & Sauvageons \\
\hline $1-2$ & 0 & 0 \\
\hline $2-3$ & 30,23 & 29,55 \\
\hline $3-4$ & 20,54 & 22,59 \\
\hline $4-5$ & 22,22 & 18,78 \\
\hline $5-6$ & 13,64 & 3,01 \\
\hline $6-7$ & 13,19 & 11,54 \\
\hline $7-8$ & 11,18 & 13,63 \\
\hline $8-9$ & 10,37 & 11,53 \\
\hline $9-10$ & 9,68 & 6,4 \\
\hline $10-11$ & 8,43 & 12,03 \\
\hline $11-12$ & 8,3 & 9,22 \\
\hline & & \\
\hline
\end{tabular}


During the first two weeks there was no elongation, but probably a foliar production that will promote elongation by elaboration of materials. The highest growth rate is observed between the 2nd and 3rd week in both cases. Over time for the seedlings, the growth rate is initially variable, then from the 5th week there is gradual decline. This slowdown would benefit foliar production and node differentiation. In the wild, there are two periods: from the 2 nd to the 3 rd week when the rate of growth decreases; then there is a slow recovery that lasts three weeks. From the 7th to the 10th week, there is a decline in growth rate. The recovery takes place from the 11th to the 12 th week.

It therefore appears that the growth rate differs between the two types of plants. In the wild, there has been a transfer from the shadow zone to the area of full light. Its growth rate would be in equation with the foliar production and the differentiation of the nodes.

\section{Average number of leaves.}

Figures 3 and 4 show the importance of foliar production of seedlings in the nursery.

\section{The seedlings}

This curve (Figure 3) looks like a staircase curve. In 12 weeks, seedlings produced an average of 6 leaves. During the first 3 weeks, leaf production is important and remains stable from the 4th to the 5th week. This indicates a growth stop that lasts two weeks. As the stopping of foliar production decreases with time, it is no longer a week between the 6th, 8th and 10th weeks. Then she goes on until the 12th week. It is very likely that this situation is caused by the action of light.

This figure shows that there are periods of leaf production and stopping, so it is not continuous with time, but it is probably related to the growth rate of the seedling stem.

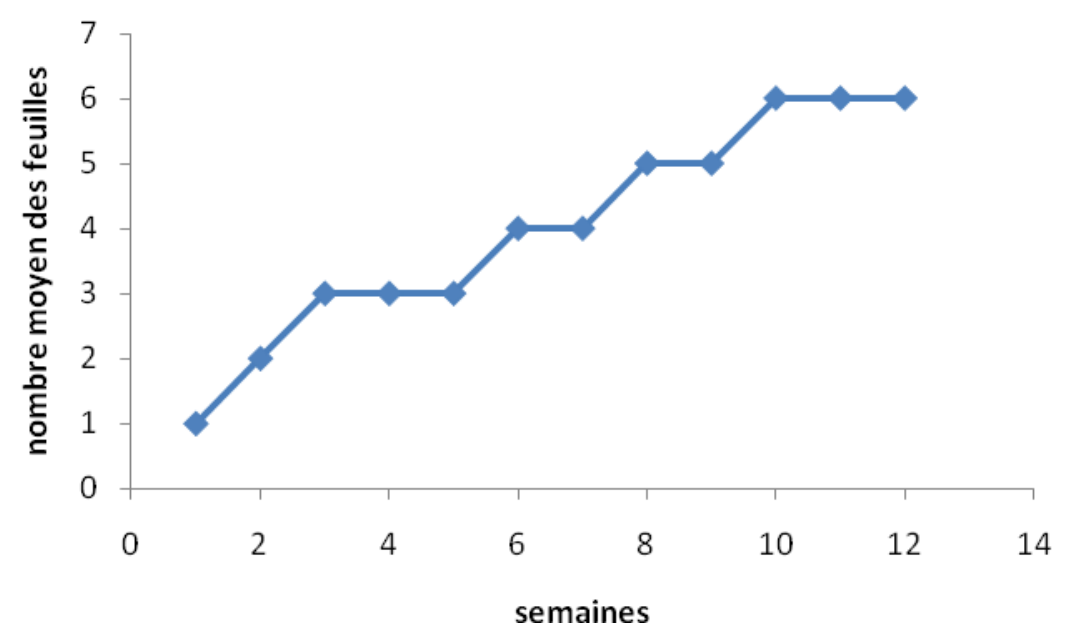


Figure 3: Average evolution of the number of seedling leaves as a function of time.

The savages

When measuring the stems of the wild (Figure 4), this curve has the appearance of a stepped curve and has the same evolution until reaching the maximum average production that corresponds to 6 leaves.

However, the curve is constant during the first 2 weeks. The foliar production is from the 3rd to the 4 th week and becomes stable at the 5th week. This stability appears again from the 7 th to the 8 th week and from the 11th to the 12th week.

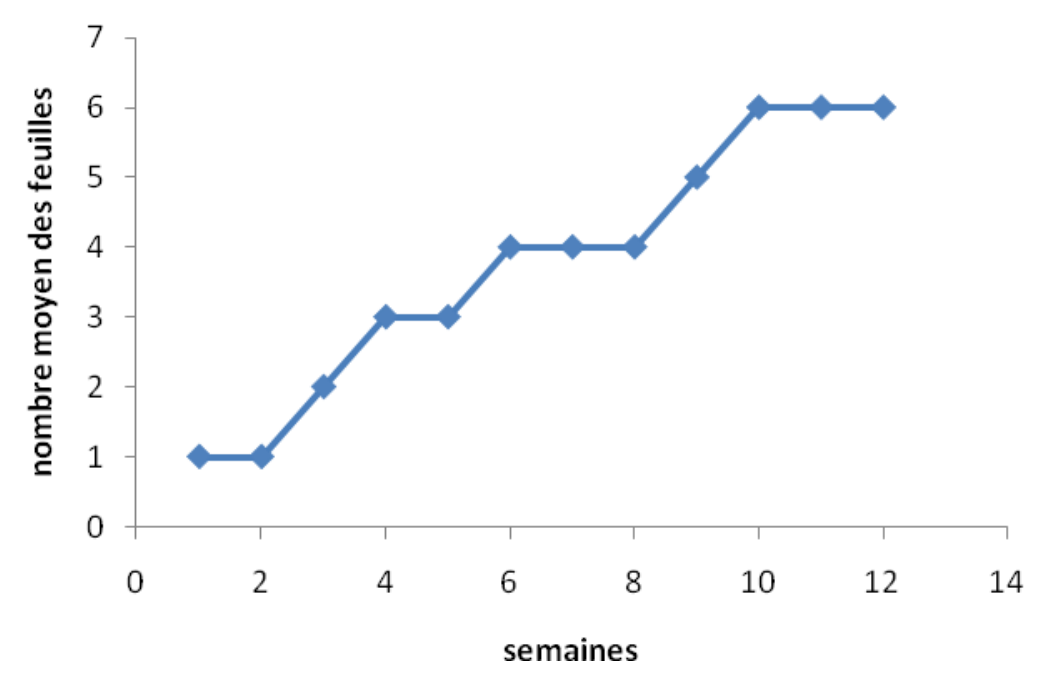

Figure 4: Average evolution of the number of wild leaves according to time

Length and width of leaves

Average length and width of seedling leaves (Figure 5).

At the level of the seedlings (Figure 5), the length increases with time, for against, for the width there is a growth-stop alternation, stop-growth until the 5th week, then a stop intervenes of the 5 th to the 7 th week and the 7 th until the 11 th week. 


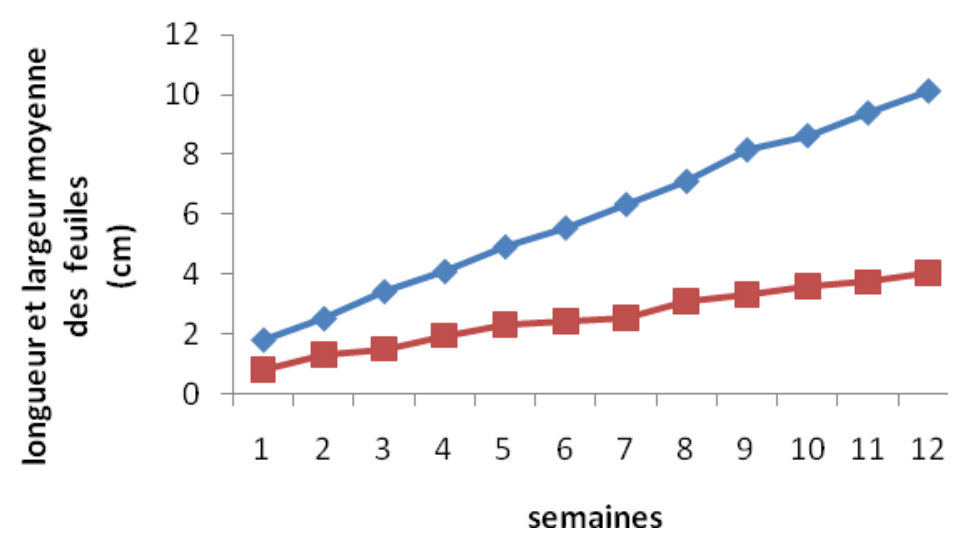

Figure 5: Average evolution of leaf length and width of seedlings as a function of time.

Leaf growth for seedlings and wildlings.

At the level of the wilds (Figure 6), there is a linear increase for the wild. The width itself has three (3) stages:

First stage: from the 1st to the 6th week;

Second stage: from the 6th to the 8th week;

Third stage: from the 8 th to the 12 th week.

Thus, it appears that the growth that is that of seedlings or wildlings, is a synchronized growth. Leaves do not develop in the same way in both seedlings and wild plants.

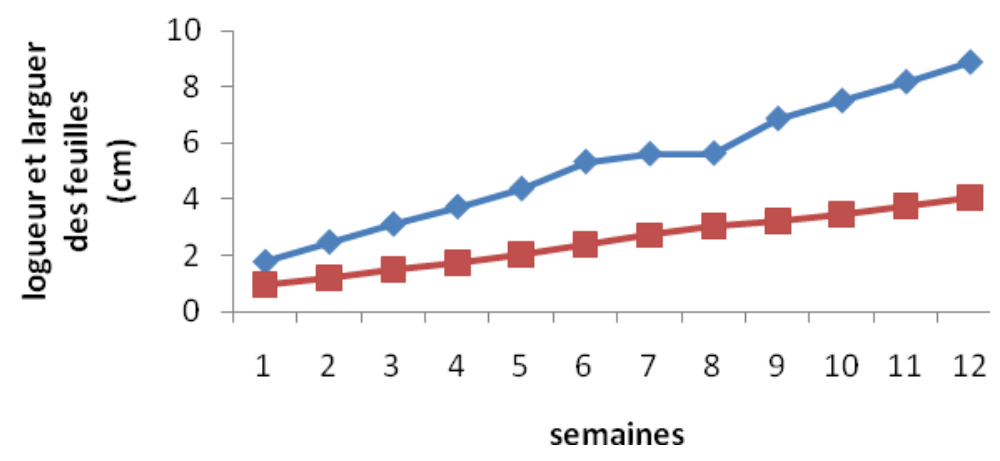

Figure 6: Average evolution of the length and width of leaves of wild vines as a function of time. The plastochronal rhythm is calculated by the following formula:

$$
\mathrm{Hb}-\mathrm{H} \text { aX } 100
$$


The plastochronal rhythm (Table 3) is different between the two (2) types of plants, from the 1st to the 5th period, and this depends on the periods when growth stops. The stopping of growth is not always the same: from the 3rd to the 4th week, from the 6th to the 7th and from the 8th to the 9 th week for the seedlings. From the 1 st to the 2 nd, from the 7 th to the 8 th week for the wild.

The percentage during the leaf production period does not change regardless of the period and type of plant. However, there are identical periods when we notice a foliar production for example 2nd and 3rd week, 5th and 6th week, 9th and 10th week. From the 10th to the 12th week there is no leaf production but we notice a lengthening of the stems.

Table 3: Calculation of plastochronal rhythm versus time by species

\begin{tabular}{|l|l|l|}
\hline $\begin{array}{l}\text { Periods per } \\
\text { week }\end{array}$ & Seedlings & Sauvageons \\
\hline $1-2$ & 14,28 & 0 \\
\hline $2-3$ & 14,28 & 14,28 \\
\hline $3-4$ & 0 & 14,28 \\
\hline $4-5$ & 0 & 0 \\
\hline $5-6$ & 14,28 & 14,28 \\
\hline $6-7$ & 0 & 0 \\
\hline $7-8$ & 14,28 & 0 \\
\hline $8-9$ & 0 & 14,28 \\
\hline $9-10$ & 14,28 & 14,28 \\
\hline $10-11$ & 0 & 0 \\
\hline $11-12$ & 0 & 0 \\
\hline
\end{tabular}

\section{Average number of nodes}

\section{The seedlings}

Figures 7 and 8 illustrate the average production of the number of nursery nodes. This curve has a similar evolution to the leaves. This is probably due to the increase in the number of nodes that is related to leaf formation. 
Nevertheless, the first two weeks the foliar production does not vary while the number of nodes increases. As the seedling grows in height the leaf production increases and remains stable. It's a synchronized growth.

The production of the nodes is a stepped curve, it is related to the elongation of the height and the foliar production. One realizes that there are periods of formations of the nodes of the 1 st to the $3 \mathrm{rd}$ week and the $3 \mathrm{rd}$ to the 5 th week stopping periods. Note that this period of stopping the production of knots is similar to that of leaf production.

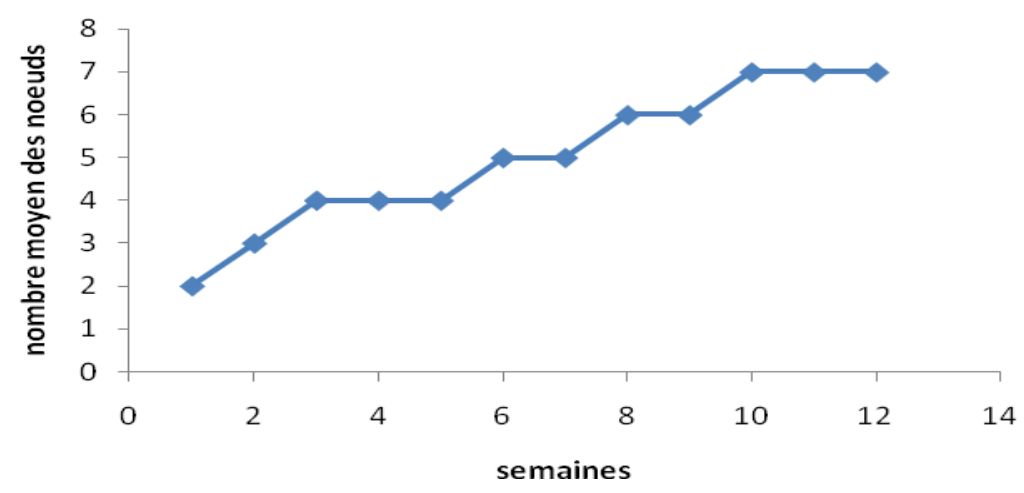

Figure 7: Average evolution of the number of seedling nodes as a function of time

The savages

The shape of this curve reflects that of the leaves, but differs from the first two weeks when it remains stationary (Figure 8).

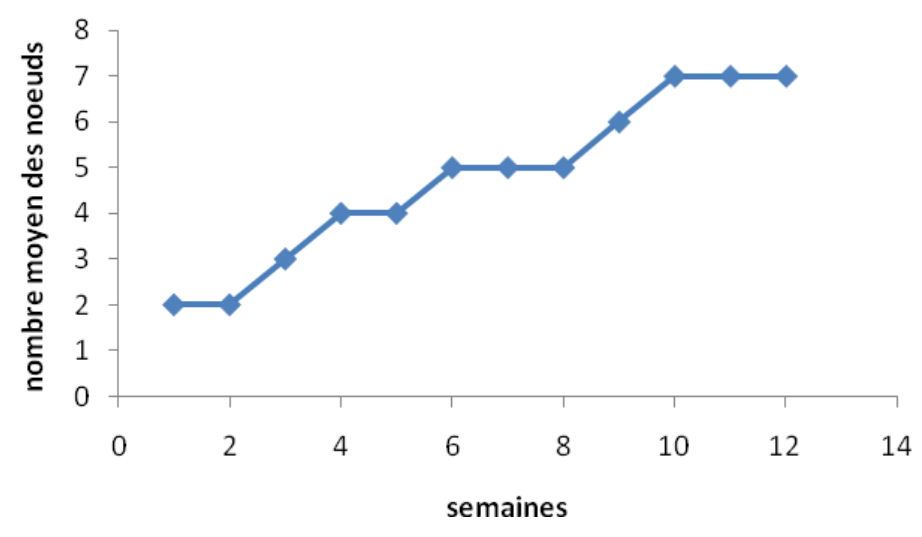

Figure 8: Average evolution of the number of knots of the wilds as a function of time.

Leaf area

Figures 9 and 10 show the evolution of the respective leaf area of seedlings and wild nursery. 


\section{The seedlings}

Measurements show that from the 1 st week to the 7 th week the leaf area is constant, then it becomes important from the 8 th to the 12th week. There appear two periods, from the 1 st to the 7 th week when the increase of the leaf surface differs each week, but from the 7th to the 12th week the increase is very fast with an average of $40,7 \mathrm{~cm} 2$.

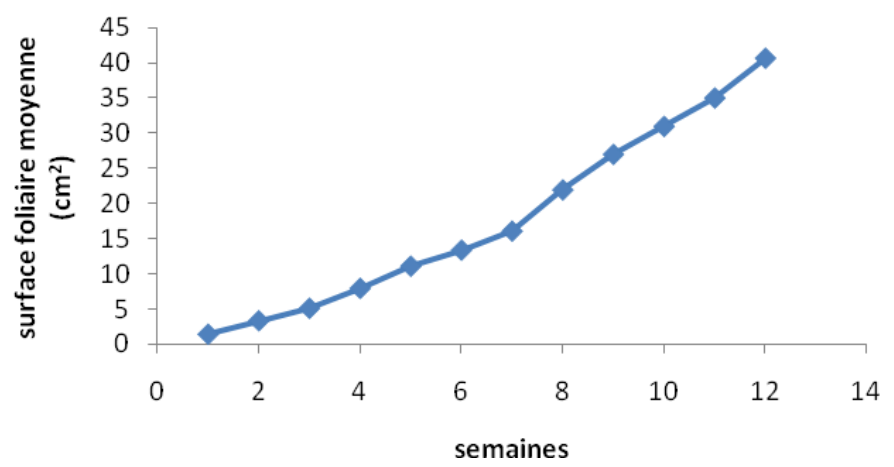

Figure $n^{\circ} 11$ : Average evolution of leaf area of seedlings as a function of time.

\section{The savages}

\section{The two curves look like a sigmoid curve.}

The leaf area of the stems is constant from the first to the fifth week when the leaves reach 11.12 $\mathrm{cm} 2$ and slowed down from the 6th to the 8th week, ie a leaf area of $21.96 \mathrm{~cm} 2$. There is significant growth from 9 th and 12 th week, which reaches $35.97 \mathrm{~cm} 2$ of average leaf area.

The rate of growth is identical but the duration of the periods changes, it is faster for the wild and longer for the seedlings.

However, the difference is significant $(5 \mathrm{~cm} 2)$ between the leaf area of the seedlings and that of the wilds. The seedlings show a good growth production in height $(14 \mathrm{~cm})$ and leaf area $(40,7 \mathrm{~cm} 2)$ on the other hand, the wild plants only have $13 \mathrm{~cm}$ of height and $35,96 \mathrm{~cm} 2$ of leaf area.

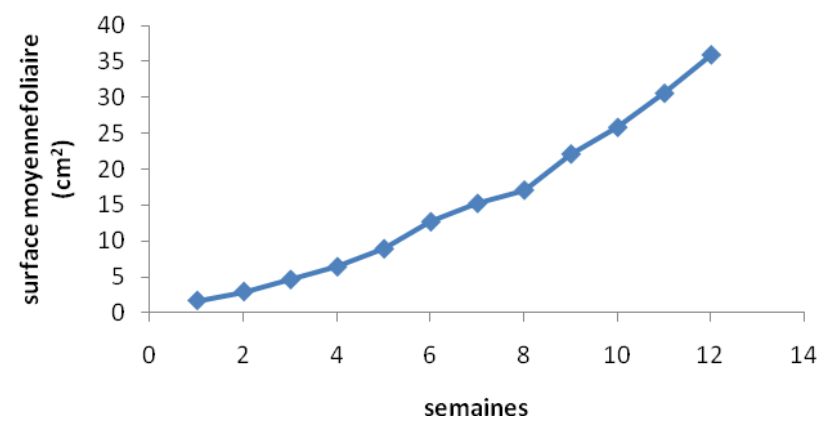


Figure ${ }^{\circ} 12$ : Average evolution of the foliar surface of the wild according to the time.

Table 5 illustrates the growth rate of seedlings and wildflowers by period

Table 5: Rate of increase of leaf area between seedlings and wilds in percentage.

\begin{tabular}{|l|l|l|}
\hline $\begin{array}{l}\text { Periods per } \\
\text { week }\end{array}$ & Seedlings & Sauvageons \\
\hline $1-2$ & 131,94 & 78,53 \\
\hline $2-3$ & 53,29 & 57,53 \\
\hline $3-4$ & 55,47 & 38,70 \\
\hline $4-5$ & 39,69 & 39,18 \\
\hline $5-6$ & 20,5 & 42,57 \\
\hline $6-7$ & 20,15 & 20,22 \\
\hline $7-8$ & 36,40 & 12,22 \\
\hline $8-9$ & 23,04 & 29,5 \\
\hline $9-10$ & 14,66 & 16,82 \\
\hline $10-11$ & 13,1 & 18,42 \\
\hline $11-12$ & 16,15 & 17,52 \\
\hline
\end{tabular}

In the seedlings, there are two periods, from the 2nd to the 7th week, when there is a gradual decrease in the leaf growth, then it responds in the 8th week and decreases to the 12th.

In the wild, the increase decreases until the 4th, then increases from the 5th to the 6th week thereafter and it responds from the 8th to the 11th week. It increases from the 9th and the 10th week to drop to the 12th. It is noted that the maximum of the increase is between the 1 st and 2 nd week.

It therefore appears the different growth rate of seedlings and wildlings. That of savages is much more variable from the third week. These variations would be related to the rate of foliar production.

However, alternately arranged leaves are better developed provide photosynthetic action primarily essential for stem elongation, node formation and leaf production.

\section{DISCUSSION}


On the emergence of Okoumé seeds

This gradual lifting is explained by the differential dormancy of the seeds. It took 23 days for the seeds to be lifted.

However, the germination of okoumé seeds occurs most often between 5 and 6 days after planting, it is normally from 3 to 6 days, the 3rd day being the maximum germination day (François B., François G Henri F., 1990).

Follow-up of the two seedlings:

Our work was aimed at comparing growth between seedlings from nursery seedlings and okoumé wildlings (Aucoumea klaineana Pierre) in seedlings from the forest. Four parameters were highlighted: stem height, production of number of leaves, appearance of number of nodes and evaluation of leaf area.

The height growth of the seedlings is continuous whereas that of the wilds is periodic.

However, the number of leaves of the seedlings is identical to that of the wild-leaves which corresponds to 6 leaves. It should be noted that the 6th leaf is at the 7th node of the young plant. This production is in accordance with the results obtained by (PANGOU, 1986) on the successive appearance of 6 to 10 single leaves alternate on the young plants of the Aucoumea klaineana Pierre, it specifies that, the 7thècoles carries the 6th sheet.

The seedlings and the Sauvignonons of Aucoumea klaineana Pierre have a steady growth in the number of nodes over all the periods going from the 1st to the 12th week. The number of nodes increases with time: from the 4th to the 5th week, the 9th week, from the 11th to the 12th week for the seedlings. From the 1st to the 2nd week, the 5th, from the 7th to the 8th week, from the 11 th to the 12 th week for the wild.

The foliar production of the seedlings is less and less similar to that of the wilds, reaching respectively 20.35 and $17.98 \mathrm{~cm} 2$ of their production. This production is ensured by the action of light.

Over a period of 12 weeks following the installation of the device (February-May) consisting of 30 seedlings and 30 wildlings, a single seedling died by an attack of insects from the 5th week, a very low mortality rate. $3 \%$.

It should be noted that the survival rates obtained from seedlings and wildflowers, respectively 96\% and 100\%, are consistent with the results obtained by DEVAL on Okoumé plants harvested in natural regeneration plots from seedlings with an excellent recovery rate that varies between 96 and $98 \%$.

According to (MENSBRUGE, 1966) When germination is very rapid (Loi, oa trichiloid), for example, the staggering of levees extends for a maximum of two weeks; in the case where it is rapid, the levees are generally observed during a period of 15 and 30 days (Excel tionally more: 65 days 1) for (hlbizzia adianthifolia). 
This rate can be very high ( 85 to $95 \%$ ), high (60 to $80 \%$ ), medium ( $60 \% \mathrm{SO}$ ), low (30 to $50 \mathrm{Oh}$ ), very low (20 to $30 \%)$.

The study of the variations of this germination rate according to the structure of the seed can be undertaken either in nursery or in forest. Several factors thus seem to play a decisive role in 10 germination rates: the degree of seed maturation; the degree of maturity of the seeds; seed integrity; the constitution of the seed.

However, there are several results on survey rates obtained by several authors and we have: for (OUAKONDO, 2012) 60\% while (BOUESSO, 2013) 39.09\%; MASSENGO KILANDI, 2010) 97.91\% while (ZALA-NKONDANI, 2009) 39.18\% and GOUOM, 2015 got him 97\%.

On the growth and production of leaves:

(MASSENGO KILANDI, 2010), counted 4 leaves in the first week in the seedling of Eucalytus citrodora transplanted in a substrate of charcoal mixed with the litter. From the second to the third week, he counted 8 leaves.

In Senna siamea for example.The work of Bouesso, 2013 showed that the second week the number of leaves was 4 leaves while the eighth week this number has increased to thirty leaves.

On the other hand, (OUAKONDO, 2012), attests that in the Limba the leaf production goes hand in hand with the height growth of the seedling. The number of leaves produced is five to the first week, then will reach extremes of twenty by the eighth week.

On increasing the length and width of the leaves:

ZALA-NKONDANI, (2009) believes that this increase is primarily dictated by the rate of emergence and the position of the seed. Nevertheless, there is a differential increase between the length and the width whatever the period of emergence and the position of the seed in the substrate.

(BOUESSO, 2013) shows that since the first week, from the neck to the cotyledon the average height is $1.5 \mathrm{~cm}$ compared to the height of the cotyledon and the first leaf respectively $2.5 \mathrm{~cm}$ from the first leaf to the second leaf and this trend is confirmed until the eighth week. (OUAKONDO, 2012), shows that in the first week the leaf reaches 1.5 to $2 \mathrm{~cm}$ in length against the eighth week, it can reach 5 to $5.5 \mathrm{~cm}$ in length. (GOUOM, 2015) showed that by the third day the largest leaf had a length of $1.5 \mathrm{~cm}$ and a width of $1 \mathrm{~cm}$, however by forty-five days the length had reached a maximum of $25 \mathrm{~cm}$ and $5 \mathrm{~cm}$ of width.

\section{From the leaf surface:}

According to (MASSENGO KILANDI, 2010) the leaf area of Eucalyptus citrodora Hook plants as a function of time shows a two-dimensional growth, the areas of proliferation and cell growth are less well defined than in the stem, in the end its growth does not increase. is not indefinite. According to the author, from the 1st to the 3rd week the growth of the leaves is slow, and a small increase appears from the 4th and 6th week. Beyond this, the growth of the leaves is very 
accentuated until the 9th week. In this study, this leaf area is seen to be sawtooth and stabilized around the ninth week.

\section{CONCLUSION}

At the end of our study, seedlings and wildlings have the same number of leaves and nodes respectively 6 and 7 , while their respective average heights $14 \mathrm{~cm}$ and $13 \mathrm{~cm}$ are different, which corresponds to $40.7 \mathrm{~cm} 2$ and $35.96 \mathrm{~cm} 2$ of surface foliar.

However, there is a significant difference $(5 \mathrm{~cm} 2)$ between leaf area of seedlings and that of wildlings. The seedlings show a good growth production in height $(14 \mathrm{~cm})$ and leaf area $(40,7 \mathrm{~cm} 2)$ on the other hand, the wild plants only have $13 \mathrm{~cm}$ of height and $35,96 \mathrm{~cm} 2$ of leaf area.

It should be noted that the results are expressed in the form of tables and figures, they are averages out of 30. The comparison between seedlings and wildlings is made on the basis of growth rate of the stem and expressed leaf area increase. percentage (\%). We made a statistical test on the comparison of means to appreciate the evolution of the leaf surface.

Further studies can be carried out with regard to the identification of the parent, by the selection of seed trees in forests according to their physiological and phonological aspect. The selected species will represent the seed companies.

\section{REFERENCES}

National Transitional Council., 2000. Law No. 16-2000 of 20 November on the Forest Code in the Republic of Congo $32 \mathrm{p}$.

BOUNDZANGA, G C., 2005. Global Forest Resources Assessment Congo. FAO National Report 68 p.

BOUESSO J. L.C., 2013. Contribution to the study of the germination of Senna siamea at the National Reforestation Service. End of training report to obtain the Diploma of Engineer of Rural Development Works. Institute of Rural Development, Marien Ngouabi University 26p.

FAO 2012: Environmental Impact Assessment: Guidelines for 44p Field Projects

François B., François G., Henri F., 1990. Global, regional and national incidence, prevalence and years lived with disability for 301 acute and chronic diseases and injuries in 188 countries, 1990-2013: a systematic analysis for the Global Burden of Disease Study2013 98p

Gami N., and Doumenge C., 2001. The actors of forest management in Central and West Africa. Working documents of the FORAFRI project. Libreville (Gabon) 66p

GOUOM, O., 2015. Contribution to the germination and growth study of Safoutier seedlings (Dacryodes edulis). End-of-training dissertation with a view to obtaining the Diploma of License option: Vegetable Productions. National School of Agronomy and Forestry, Marien Ngouabi University 40p. 
MAPOLA, G., 2000. Practical guide for the reforestor and the silviculturist in the establishment and management of reforested perimeter stands by traditional stations and UPARA in Congo pp. 4-9

MASSENGO KILANDI C. P., 2010. Production process and monitoring of Eucalyptus (Citriodora hook) seedlings in nursery, in nursery: Case of Kitele semi-industrial nursery. End of training report to obtain the Diploma of Engineer of Rural Development Works. Institute of Rural Development, Marien Ngouabi University 52p.

MENSBRUGE, G., 1966. Germination and seedlings of tree species of the humid dense forest of Ivory Coast. CTFT, Nogent-sur-Marne (Seine), France. 300p.

OUAKONDO Y. G. K., 2012. Conduct of Terminalia mantaly H. Perrier carried out at the National Reforestation Service of Brazzaville. End of training report to obtain the Diploma of Engineer of Rural Development Works. Institute of Rural Development, Marien Ngouabi University $28 \mathrm{p}$.

CBFP, 2006. Congo Basin Forest Partnership, State of the Forests. 256p.

PANGOU, S.V., 1986. Seed germination and seedling development of four tropical hardwood species. University of Nancy, Mémoire de DEA. 131p.

Sist, P., Dykstra, D., Fimbel, R., 1998. Reduced impact logging guidelines for lowland and hill dipterocarp forest in Indonesia. CIFOR occasional paper $n{ }^{\circ}$ 15.Directives for the application of the techniques of low impact exploitation (EFI) in Gabon: objectives, main and stakes. FORAFRI seminar in Libreville- Session 4: exploitation, planning, management, 26p.

ZALA-NKONDANI, E.F., 2009. Germination test of seeds of Cola nitida (Vent.) Schott and Endl. (Sterculiaceae) in the Ex-ORSTOM site, Brazzaville. End of training report to obtain the Diploma of Engineer of Rural Development Works. Institute of Rural Development, Marien Ngouabi University 28p. 